\title{
Designing and Implementing of Dynamic Technique for Detecting Learning Style Using Literature Based Approach
}

\author{
Hadeel Ateia ${ }^{1}$ and Thair Hamtini ${ }^{2}$ \\ ${ }^{1}$ Department of Computer Information Systems, The University Of Jordan \\ ${ }^{2}$ Department of Computer Information Systems, The University Of Jordan \\ ${ }^{1}$ Hadeel.ateia.ab@gmail.com, ${ }^{2}$ Thamtini2013@gmail.com
}

\begin{abstract}
This paper is a part of ongoing research that tries to approve our hypothesis about adaptive personalization in web-based learning systems; we are debating that building online learning environments with the ability to detect learners learning style dynamically by observing their behaviour and then presenting learning material based on the detected learning style is more effective than using ILS questionnaire. In an earlier work, we provided a dynamic technique that identifies learners VAK learning styles according to their behaviour in the learning environment influenced by literature approach, in this paper we have modified our technique and re-proposed it. First, we connected behavioural patterns (time, visits and answer patterns) to the features (contents, outlines, group forums, examples, case studies, exercises and assessments), then we defined the effect each VAK learning style will have on each pattern. Next, we described three general rules and three algorithms that should detect the learning style. Now we are in the process of building two online learning environments to test and confirm the differences between dynamic learning style detection _ based on our technique _and the traditional ILS questionnaire environments; we choose a course called 'Computer Skills for medicine faculty students', which is provided from the faculty of Information Technology at the University of Jordan; the results of the planed experiment will be saved and analysed using SPSS.
\end{abstract}

Keywords: Personalization; VAK; Learning Style; web-based Learning; Literature based approach

\section{Introduction}

The Learning process has been affected by the huge expansion of technology production; people are using the internet and technologies every day to get information, services, entertainment, and learning. The new revolution in technology makes it possible to change how and what to be delivered in online learning. Based on that, the shape of traditional classroom where both student and teacher are physically allocated in the same place and working face-to-face was reshaped by adding the distance learning concept, which limited the effect of place and time over learning [19]. As a result; information networks and multimedia combination, on-line learning, e-learning or web-based learning terms appeared. Web-based learning makes it possible to share different kinds of media, documents, videos, audio, etc. throughout a web-based course (e-course) [11].

E-learning platforms are commonly utilized as a part of the PC that assist learning, particularly for open and distance learning given by organizations, colleges or other instructive establishments [10]. To empower better learning the use of online assets has been mixed effectively with education [3].

People tend to have different needs; they realize and process information differently [9], these individual dissimilarity influence people learning. It is the cause behind why few learners think that it is simple to learn a specific course, while others see the same 
course hard [10]. The way individuals prefer to learn has a major influence on learning achievements and outcomes, learners most of the time need a learning domain that is customized according to their demands [14]. Learning material that is designed to suit the students chosen way of learning aims to make learning easier [23].

Several researchers pointed to the importance of providing learners with personalized interface that support individual specific preferences and meet their learning habits, they also mentioned that these customized interfaces are much effective in web-based learning than the "one size fits all" ones [4][16][17]. In computer science personalization is the system capability to adjust the requirements of each user [14].

It has been identified that hypermedia systems are the best way to provide personalized learning support or guidance by identifying the personal characteristics of the learner, adapting learning paths or the way of presenting learning material. [25]

One of the most significant parameters in the process of defining individual differences is learning styles [20].

In this paper, we are aiming to design a personalized learning environment based on Visual-Auditory-Kinesthetic (VAK) learning styles theory; this environment will offer a technique to adapt learner learning style automatically by observing learner behaviour on the environment without overloading learners with questionnaire. Hopefully, the system would enhance the learning process by matching the learning content with the learner learning style.

\section{Learning Style}

The learning style expression has been used for a while to depict the way a person acknowledges and handles information or data through the learning process. It worries about how people commonly consider, recollect or tackle problems [4]. Learning styles influence how persons realize, how they act in a learning group, how they partake in learning exercises, construct relations and take care of the issues [5].

The Visual-Auditory-Kinesthetic (VAK), Kolb's and Silverman (FSLSM) are the most well-known learning style models [14].

Our main concern in this study is the VAK model; which classifies learning styles into three; (i) visual learning style where people in this group mainly use their eyes, they prefer to learn by seeing and watching, they only understand information if it is written as a text or displayed as a picture, figure, table or a video. (ii) Auditory learning style; this group encompasses people who prefer to use their ears and listen carefully, they most of the time find written text difficult. (iii) Kinesthetic learning style or called tactile, includes people who learn by doing things themselves, they will be enthusiastically touching things, putting things together or even break things into parts [23].

The learning styles field is still a perplexing one, in spite of the fact that number of researches had been directed, some essential inquiries are still open. [10] The learning styles are regularly misapplied and are restricted in what they can accomplish [10].

The learning studies, these days are dealing with a new trend where learning styles detection in web-based learning systems need to be done automatically [6].

\subsection{Learning Style Detection: Data Driven Approach or Literature Based Approach?}

Learners learning style detection is currently done in one of two ways (Data Driven Approach or Literature Based Approach). (i) Data driven approach uses the predefined ILS questionnaires that provide students with several questions and based on their answers they will be assigned to most proper learning style that fits each [8]. (ii) Literature based approach; focuses on the literature fact, which mentions that when students are facing same environmental conditions they will have the same behaviour regarding the material. Generally, literature based approach concentrates on learners and 
their behaviour to have a clear hint on the student learning style tendencies, and then it tries to develop a rule based mechanism which will detect the learner learning style [8][25]. Distinguishing learning styles based on this approach means that there is a need to observe learner behaviour patterns [14].

Data driven approach has been critiqued; for most of the learners. Because, questionnaire answering is an exhausting assignment that requires an extra work, it is a boring procedure for them; they might have a tendency to pick answers randomly. Most questionnaires expect that learners know about their learning preferences, however, this is not generally the case [7].

Adaptive web-based learning started to move from providing an ILS questionnaire inorder to detect the learner's learning style into automatic detection based on their behaviour and interactivity with the learning environment resources. This research is a part of ongoing research that is focusing on the VAK learning styles. It investigates the effect of building online learning environment that has a dynamic technique to detect student learning style automatically based on her/his behaviour during the on-line learning process.

\subsection{Why VAK?}

According to Moayyeri, Intel Corporation in 2007 stated that VAK learning styles theory has proven to be a popular and simple way to identify different learning styles, he also said that the practical mode of VAK assessment, which mainly asks learners how they receive information, is a strong reason for using it in the educational field [18].

VAK is considered to be the base for several learning style models. It is a well-known model since it is compatible with the principles of interactive learning systems design and easy to understand its results [15]. VAK in recent years turned to be a preferable of the accelerated learning community since its principles and benefits extend to all types of learning and development, away from its earlier applications [12].

In the next sections we; (i) explored the previously done work in the learning style detection in web-based learning environments, (ii) discussed the methodology followed in this research where our dynamic suggested technique pattern of behaviour, rules and algorithms were described, (iii) mentioned our major hypothesis and the way we are trying to test and approve it.

\section{Related Work}

Learning styles consideration in web-based learning environments is a part of the personalization process that took a great attention in the last decade. Several researches have been conducted to the term of providing personalized interfaces within online learning environments, several techniques were proposed with the aim of helping to improve learning styles adoption and detection.

An automatic student modelling approach was presented in learning management system (LMS) by Graf, Liu, Chen and Yang [9]. The researchers' main concern was identifying students learning style based on FSLSM model. They derived the behaviour patterns of their approach from previous learning style literature. They have also defined a simple rule-based method to calculate the learning styles. A sample of 75 students participated in evaluating this approach, to check its validity. They were given the ILS questionnaire to decide their learning styles. The results were compared with the ones that the researchers got from their detection approach.

In 2010 Graf and Liu studied the navigational behaviour of learners in a LMS course in order to use the findings for the enhancement and improvement of online learning systems adaptively, they also worked with FSLSM model. Their results are a great addition to the adaptive learning systems [10]. 
Researchers in [13] implemented FSLSM learning styles auto-detection tool over a web-based learning environment, they tried to analyse learners' behaviour by monitoring their interaction with the material in web pages using a social bookmarking service.

In [22] the author built an adaptive system based on two learning style models, VAK and FSLSM. The researcher connected the three VAK learning styles with the global and sequential learning styles in FSLSM model. Based on those connections, six different material presentations were proposed.

In April 2013 Researchers of [21] spotted the learning behaviour of students and logged it in a data log, they did not tend to make the learners answer ILS questionnaire. The research defined an approach called Triple-Characteristic Model (TCM) where the focus was not only on students' learning styles (FSLM), but also accumulated motivation and knowledge abilities. The defined concept has three layers; learning layer, characteristic layer, and personalization layer.

Authors in [2] proposed an approach to detect the learning style of students based on their behaviour in learning management systems, they worked with FSLSM learning styles, where they defined several behavioural patterns first. Then, they showed the relevant pattern for each learning style category and applied some rules to calculate the learning style of the students.

In [15] the researchers chose to work with VAK model and find a way to auto detect the learning style of learners, they defined three simple rules to calculate learning styles based on learners' behavioural patterns. The chosen behavioural patterns were defined before by Mr. Khan in 2009. The framework that was proposed includes: interface engine and a knowledge base engine. After learner sign up, she/he will be asked to work with an exercise to define her/his learning style, the learning material should be built based on the detected learning style.

In [5] the researchers proposed a mechanism for analysing e-course material in learning management systems (LMS) based on the literature from FSLSM learning styles. Beside that, they delivered an interactive instrument that utilizes this mechanism and offers a support to educators in learning environments. The system they had built was designed to extend the LMSs functionalities. It consists of layers, data layer, calculation component layer and the user interface layer.

In order to distinguish between learners according to their behaviour on the Moodle course, the authors of [1] proposed a model for FSLSM learning styles. Testing phase was done by including thirty-five students in a Data Structure on-line course provided via Moodle in Majmaah University at KSA. The students behaviour was extracted from Moodle logs, the determined learning styles from the implemented model was assessed using a quiz at the end of the course.

In [24] the authors offered a web-based decision support system, which computes the learning style in light of student visits and time spent on the given learning materials. They used three fundamental formulas to identify learning style (time spent ratio, visits ratio and the average between time ratio and visits ratio). Based on the average ratio they recommended a basic rule, which classifies learning styles into three types; (i) weak when the ratio is between 0 and 0.3 , (ii) moderate if it is more than 0.3 and less than 0.7 , and (iii) strong if it is less than 1 and more than 0.7 .

In our previous research [14] we portrayed a dynamic technique for distinguishing learners learning styles in view of their behaviour in the learning environment affected by literature based approach. Our proposed technique aimed to find the best suitable learning style from VAK model for each learner. We focused on (contents, case studies, examples, exercises and assessments) learning material features, and (staying time, visits, and answers) behavioural patterns. In addition, we connected the features and the patterns to VAK learning styles to determine the effect of each learning style on each pattern. Moreover, we suggested some rules and algorithms to be used in the learning style auto detection. Finally, in-order to test our technique we delivered a pilot e-learning 
environment and we compared the learning style that was detected by our technique with the one we got from a VAK questionnaire. Eighteen person participated and learned using the pilot learning environment.

Most of the researches that were conducted on web-based personalization based on learning styles focused on FSLSM model, a few number worked with VAK model. We were unable to find a detailed research on how to implement the VAK learning styles in web-based learning systems? Or what are the exact features that need to be monitored? Also, we did not explore a research that explained how VAK learning styles are effected by features behavioural patterns?

\section{Methodology}

This research aims to design an adaptive web-based learning system based on VAK learning styles theory and our earlier work suggested technique in [14]. The system should be able to detect the learning style of learners based on their behaviour in the learning environment, and then display learning material that suits each learner learning preferences based on their current learning style.

In the next section, we provide a brief about the previously published detection technique pattern of behaviour, rules and algorithms.

\section{Behaviour Patterns}

Behaviour patterns observation is the first step in automatic detection of learning style; these patterns can give a good indicator about the learner inclinations. In-order to observe the patterns of behaviour, there is a need to connect each pattern to one or more of the learning material features.

We are focusing on time, visits and answer patterns, we connected these patterns to the features, contents, outlines, group forums, examples, case studies, exercises and assessments. Outlines and group forums are two new added features, which were not included in our last research [14]. The mentioned patterns and features are provided in Table 1 below. The first column, demonstrates the features, which will be monitored. Second column displays what kind of behaviour patterns to monitor and observe.

The next step was to define the effect of each pattern over the VAK learning styles which is presented in Table 2; the usage of $(+)$ symbol indicates a higher occurrence of the pattern while the symbol (-) means a lower occurrence.

Table 1. Features and Behavioural Patterns

\begin{tabular}{|l|l|}
\hline \multicolumn{1}{|c|}{ Feature } & \multicolumn{1}{|c|}{ Behavioral Patterns } \\
\hline \multirow{5}{*}{ Content } & content_visit_on_mouse_click \\
\cline { 2 - 2 } & content_stay_time \\
\cline { 2 - 2 } & non_graphic_content_stay_time \\
\cline { 2 - 2 } & graphic_content_time \\
\cline { 2 - 2 } & non_graphic_content_visit_on_mouse_click \\
\cline { 2 - 2 } & graphic_content_visit_on_mouse_click \\
\hline \multirow{3}{*}{ Outlines } & outlines_visits_on_mouse_click \\
\cline { 2 - 2 } & outlines_stay_time \\
\hline \multirow{3}{*}{ Exoup forums } & forums_visits_on_mouse_click \\
\cline { 2 - 2 } & forums_stay_time \\
\hline \multirow{2}{*}{ Case Studies } & example_visit_on_mouse_click \\
\cline { 2 - 2 } & example_stay_time \\
\cline { 2 - 2 } Exercises & case_studies_visit_on_mouse_click \\
\cline { 2 - 2 } & case_studies_stay_time \\
\hline
\end{tabular}




\begin{tabular}{|l|l|}
\hline \multirow{4}{*}{$\begin{array}{l}\text { Assessment } \\
\text { and quizzes }\end{array}$} & exercise_stay_time \\
\cline { 2 - 2 } & exercise_result \\
\cline { 2 - 2 } & num_correct_answers_graphic_content \\
\cline { 2 - 2 } & num_correct_answers_text \\
\cline { 2 - 2 } & answering_order_attemp_random \\
\cline { 2 - 2 } & answering_order_attemp_sequential \\
\cline { 2 - 2 } & num_of_unanswered_questions \\
\cline { 2 - 2 } & num_of_answered_questions \\
\cline { 2 - 2 } & assessment_visit_on_mouse_click \\
\cline { 2 - 2 } & assessment_stay_time \\
\hline
\end{tabular}

\section{Rule Base}

One of the major steps in defining learning styles using literature based approach is defining some rules, these rules are considered with the pattern of behaviour defined by the researchers. In our research we will use three main rules, which we explored in [14], the rules are related to (staying time, visits and answers) patterns.

\subsection{Staying Time Pattern Rule}

This rule is considered with the staying time pattern, the $\left(\right.$ Time $\left._{\text {Predicted }}\right)$ for each learning object is measured, stored and then compared to the (Time Actual $)$ to come up with the time ratio $\left(R T_{L S}\right)$ for each learning object.

$$
R T_{L S}=\sum \text { Time }_{\text {Actual }} / \sum \text { Time }_{\text {Predicted }}
$$

The calculated ratios $\left(R T_{L S}\right)$ of each object need to be then compared to each other inorder to define learning style.

\subsection{Visits Pattern Rule}

We need for each provided object to find the total number of object visits $\left(\right.$ Object $\left._{\text {Visit }}\right)$ and the total count of objects $\left(\right.$ Object $\left._{\#}\right)$, then we can find the visit ratio $\left(R V_{L S}\right)$.

$$
R V_{L S}=\sum \text { object }_{\text {Visit }} / \sum \text { object }_{\#}
$$

\begin{tabular}{|c|c|c|c|c|}
\hline Feature & Behavioral Patterns & Visual & Auditory & Kinesthetic \\
\hline \multirow{6}{*}{ Content } & content_visit_on_mouse_click & - & + & - \\
\hline & content_stay_time & - & + & - \\
\hline & non_graphic_content_stay_time & + & - & - \\
\hline & graphic_content_time & - & + & - \\
\hline & non_graphic_content_visit_on_mouse_click & - & + & \\
\hline & graphic_content_visit_on_mouse_click & + & - & \\
\hline \multirow{2}{*}{ Outlines } & outlines_visits_on_mouse_click & - & + & - \\
\hline & outlines_stay_time & - & + & - \\
\hline \multirow{2}{*}{ Group forums } & forums_visits_on_mouse_click & - & & + \\
\hline & forums_stay_time & - & + & + \\
\hline \multirow{2}{*}{ Examples } & example_visit_on_mouse_click & & + & - \\
\hline & example_stay_time & & + & - \\
\hline \multirow{2}{*}{ Case Studies } & case_studies_visit_on_mouse_click & & & + \\
\hline & case_studies_stay_time & & & + \\
\hline \multirow{3}{*}{ Exercises } & exercise_visit_on_mouse_click & & - & + \\
\hline & exercise_stay_time & & - & + \\
\hline & exercise_result & & & - \\
\hline
\end{tabular}

\section{Table 2. VAK Learning Style and Effect over Behavioural Patterns}




\begin{tabular}{|l|l|c|c|c|}
\hline \multirow{4}{*}{$\begin{array}{l}\text { Assessment } \\
\text { and quizzes }\end{array}$} & num_correct_answers_graphic_content & + & - & \\
\cline { 2 - 5 } & num_correct_answers_text & - & + & \\
\cline { 2 - 5 } & answering_order_attemp_random & + & & + \\
\cline { 2 - 5 } & answering_order_attemp_sequential & & + & \\
\cline { 2 - 5 } & num_of_unanswered_questions & & & - \\
\cline { 2 - 5 } & num_of_answered_questions & & & + \\
\cline { 2 - 5 } & assessment_visit_on_mouse_click & & & + \\
\cline { 2 - 5 } & assessment_stay_time & & & + \\
\hline
\end{tabular}

\subsection{Answers Pattern Rule}

The answers of exercises and assignment features are the ones that will be related to this pattern; several ratios were defined; correct answers ratio (RCALS), incorrect answers ratio (RIALS), left questions without answering ratio (RLALS), answered questions ratio (RAALS) and answering order attempts ratios; random (RRALS) and sequential (RSALS). These ratios will be compared to each other to come up with learning style indication.

$$
\begin{aligned}
& R C A_{L S}=\sum \text { Correct }_{\text {Answers }} / \sum \text { Answers }_{\#} \\
& R I A_{L S}=\sum \text { Incorrect }_{\text {Answers }} / \sum \text { Answers }_{\#} \\
& R L A_{L S}=\sum \text { Left }_{\text {Questions }} / \sum \text { Questions }_{\#} \\
& R A A_{L S}=\sum \text { Answered }_{\text {Questions }} / \Sigma \text { Questions }_{\#} \\
& R R A_{L S}=\sum \text { Random }_{\text {Attempts }} / \Sigma \text { Questions } \\
& R S A_{L S}=\sum \text { Sequential }_{\text {Attempts }} / \sum \text { Questions }_{\#}
\end{aligned}
$$

The defined rules were then converted into algorithms that can be easily coded and implemented to determine the learning style; the algorithms were modified to cover the new added features (outlines and group forums).

\section{Algorithms and Learning Style Estimation}

Three algorithms were defined; each one is related to one of the monitored patterns; in each one there are three numeric variables that present VAK model learning styles (visual, auditory and kinesthetic); the variables will hold an initial value of 0 , the value will be modified by adding one based on the algorithms executed conditions.

\subsection{First Algorithm -Stay_Time_Factor}

Step $1 \rightarrow$ Calc. $\left(\right.$ Time $_{\text {Predicted }}$ ) for contents, outlines, group forums, examples, case studies, exercises and assessments.

Step $2 \rightarrow$ Calc. $\left(R T_{L S}\right)$ for contents, outlines, group forums, examples, case studies, exercises, assessments.

Step $3 \rightarrow$ Detect Learning Style,

$$
\begin{aligned}
& \text { IF }\left(R T_{L S} \text { OF Assessments }\right)>\left(R T_{L S} \text { OF Contents }\right) \\
& \text { THEN (Kinesthetic++) } \\
& \text { IF }\left(R T_{L S} \text { OF Contents }\right)>\left(\text { Time }_{\text {Predicted }} \text { OF Contents }\right) \\
& \text { THEN (Auditory++) } \\
& \text { ELSE (Visual++) } \\
& \text { IF }\left(R T_{L S} \text { OF Examples }\right)>\left(\text { Time }_{\text {Predicted }} \text { OF Examples }\right)
\end{aligned}
$$


THEN (Auditory ++)

ELSE (Kinesthetic++)

IF $\left(R T_{L S}\right.$ OF Case_Studies $)>\left(\right.$ Time $_{\text {Predicted }}$ OF Case_Studies)

THEN (Kinesthetic++)

IF $\left(R T_{L S}\right.$ OF Graphic_Contents $)>\left(R T_{L S}\right.$ OF Non_Graphic_Contents $)$

THEN (Auditory++)

ELSE (Visual++)

IF $\left(R T_{L S}\right.$ OF Exercises $)>\left(\right.$ Time $_{\text {Predicted }}$ OF Exercises $)$

THEN (Kinesthetic++)

IF $\left(R T_{L S}\right.$ OF Outlines) > (Time Predicted $_{\text {OF Outlines })}$

THEN (Auditory++)

IF $\left(R T_{L S}\right.$ OF Forums $)>\left(\right.$ Time $_{\text {Predicted }}$ OF Forums $)$

THEN (Auditory++, Kinesthetic++)

ELSE (Visual++)

Output $:\{$ Visual=x, Auditory $=\mathrm{y}$, Kinesthetic $=\mathrm{z}\}$

\subsection{Second Algorithm -Visits_Time_Factor}

Step $1 \rightarrow$ Calc. $\left(R V_{L S}\right)$ for contents, outlines, group forums, examples, exercises and assessments.

Step $2 \rightarrow$ Detect Learning Style,

IF $\left(R V_{L S}\right.$ OF Contents $)>\left(R V_{L S}\right.$ OF Exercises $)$

THEN (Auditory++)

IF $\left(R V_{L S}\right.$ OF Graphics $)>\left(R V_{L S}\right.$ OF Non-Graphics $)$

THEN (Visual ++)

ELSE (Auditory++)

IF $\left(R V_{L S}\right.$ OF Exercises $)>\left(R V_{L S}\right.$ OF Content $)$

THEN (Kinesthetic ++)

IF $\left(R V_{L S}\right.$ OF Exercises $)>\left(R V_{L S}\right.$ OF Examples $)$

THEN (Kinesthetic ++)

IF $\left(R V_{L S}\right.$ OF Case Studies $)>\left(R V_{L S}\right.$ OF Content $)$

THEN (Kinesthetic++ )

$\mathrm{IF}\left(R V_{L S}\right.$ OF Assessment $)>\left(R V_{L S}\right.$ OF Content $)$

THEN (Kinesthetic ++)

IF $\left(R V_{L S}\right.$ OF Outlines $)>\left(R V_{L S}\right.$ OF Content $)$

THEN (Auditory ++ )

$\mathrm{IF}\left(R V_{L S}\right.$ OF Forums $)>\left(R V_{L S}\right.$ OF Content $)$

THEN (Kinesthetic ++) 


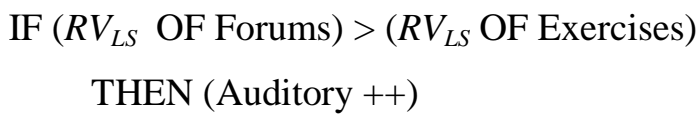

Output: $\{$ Visual=x, Auditory $=\mathrm{y}$, Kinesthetic $=\mathrm{z}\}$

\subsection{Third Algorithm - Answers_Factor}

Step $1 \rightarrow$ Calc. both $\left(R C A_{L S}\right)$ and $\left(R I A_{L S}\right)$ for graphic contents, non-graphic contents and exercises

Step $2 \rightarrow$ Calc. both $\left(R R A_{L S}\right)$ and $\left(R S A_{L S}\right)$ for assessments.

Step $3 \rightarrow$ Calc. both $\left(R A A_{L S}\right)$ and $\left(R L A_{L S}\right)$ for assessments.

Step $4 \rightarrow$ Detect Learning Style,

IF $\left(R C A_{L S}\right.$ OF Graphics $)>\left(R C A_{L S}\right.$ OF Non-Graphics $)$

THEN (Visual++)

ELSE (Auditory++)

IF $\left(R I A_{L S}\right.$ OF Graphics $)>\left(R I A_{L S}\right.$ OF Non-Graphics $)$

THEN (Auditory++)

ELSE (Visual++)

IF $\left(R I A_{L S}\right.$ OF Exercises $)>\left(R C A_{L S}\right.$ OF Exercises $)$

THEN (Kinesthetic ++)

IF $\left(R R A_{L S}\right.$ OF Assessments $)>\left(R S A_{L S}\right.$ OF Assessments $)$

THEN (Kinesthetic++, Visual++)

ELSE (Auditory++)

IF $\left(R A A_{L S}\right.$ OF Assessments $)>\left(R L A_{L S}\right.$ OF Assessments $)$

THEN (Kinesthetic ++)

ELSE (Auditory++)

Output $:\{$ Visual $=\mathrm{x}$, Auditory $=\mathrm{y}$, Kinesthetic $=\mathrm{z}\}$

The output variable with the higher value will be considered to be the current learning style of the learner.

The next section provides an overview about the research hypothesis and the experiment plan.

\section{Hypothesis and Experiment Plan}

We are hypothesizing that building personalized web-based learning environment using dynamic learning style detection techniques can enhance the learning process and boost learner achievements more than traditional approaches (ILS questionnaire).

In-order to approve our hypothesis, we have suggested a dynamic technique using literature based approach; defined general rules and provided algorithms, the technique aims to identify learner VAK learning style automatically and dynamically based on learner behaviour on any learning environment.

We are in process of building an on-line course to meet our goal. The faculty of Information Technology at the University of Jordan offered us 'computer skills' course for medicine faculty students. A monitored experiment will be conducted, the experiment will take place on two equal groups in-order to test our suggested hypothesis and 
technique. (i) First group (data driven approach) presented in Figure 1, students in this group will be asked first to sign up and then response to a VAK questionnaire to find their learning style, the learning material will be presented based on the questionnaire detected learning style. (ii) Second Group (dynamic technique) which is shown in Figure 2, learners will study from an environment that is built based on our suggested dynamic detecting module; the learning style will be detected automatically using the proposed rules and algorithms, learning material will be presented according to the learner current learning style.

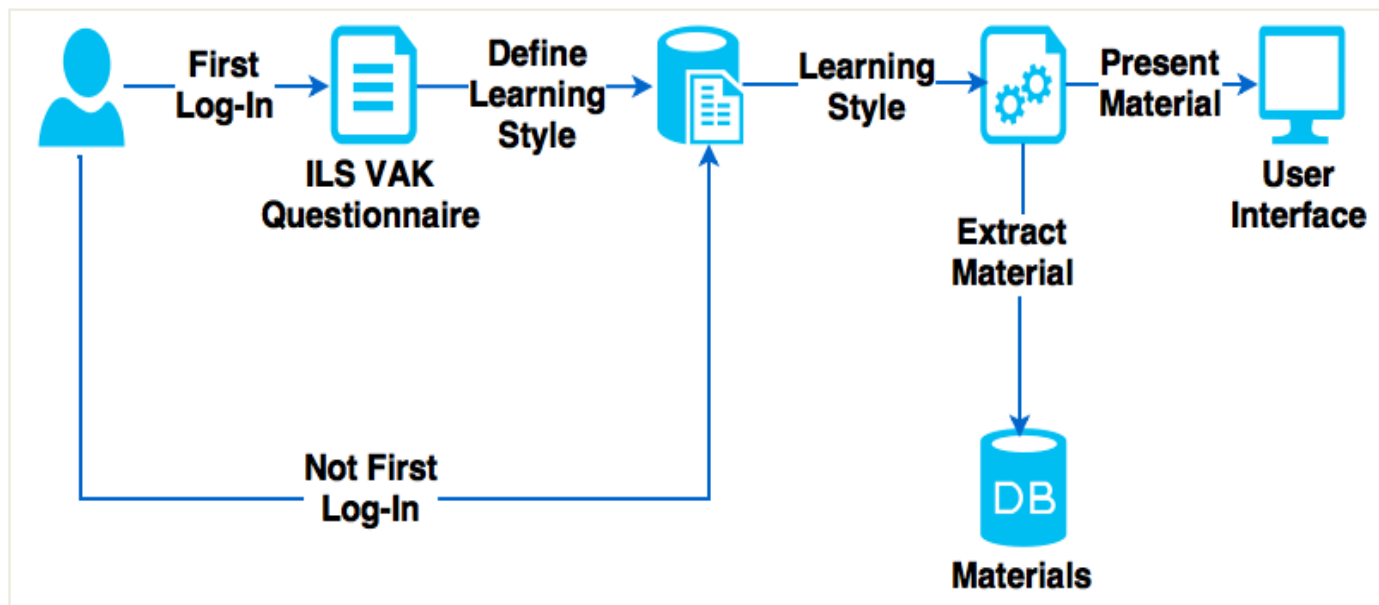

Figure 1. Experiment First Group

Both groups will take a pre-test to define the learners level and make sure that both groups are in the same cognitive level. Therefore, when the post-test results are compared, it will be fair. The results of the applied experiment will be saved and analysed using the Statistical Package for the Social Sciences (SPSS) in-order to validate the proposed technique and its effect on the learner learning achievements.

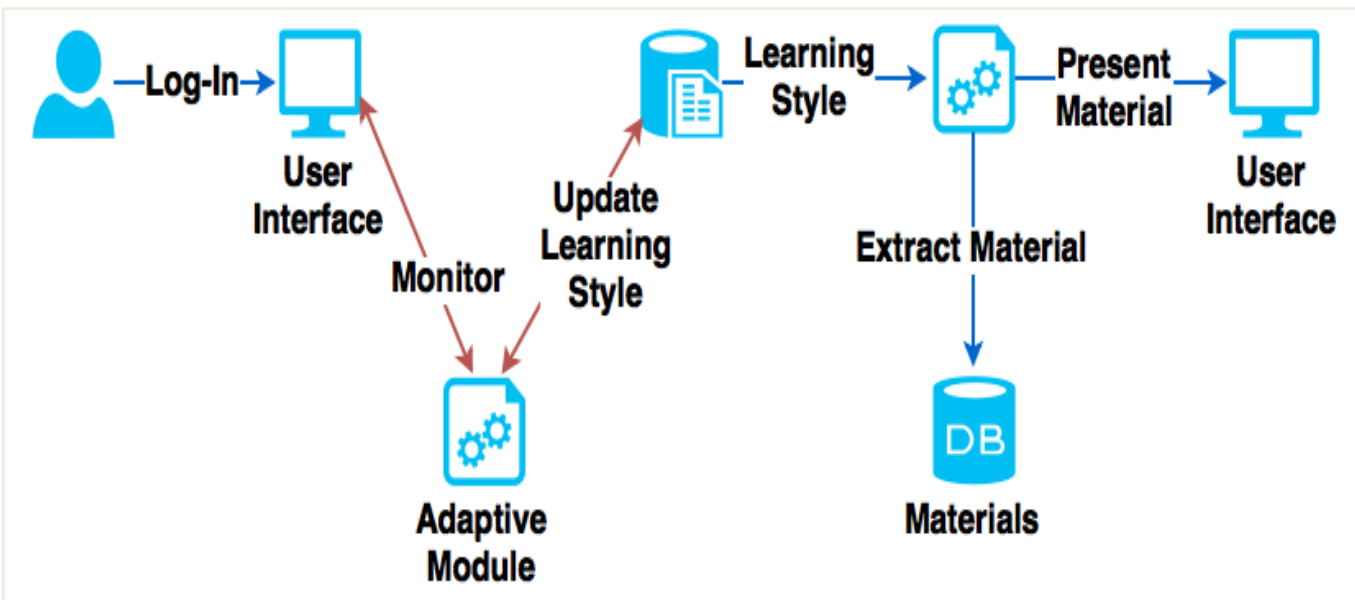

Figure 2. Experiment Second Group 


\section{Conclusion}

In this paper, we discussed the role of personalization in web-based learning environment based on learning styles theory and students' differences. We tried to explore previously done work in this field. Also, described a technique that tries to detect learners VAK learning style based on the learners' behaviour in web-based learning environment; the technique was part of our previous research [14] with some changes.

We are arguing that web-based learning systems that are supported with a dynamic approach to detect the learners learning styles are better and more effective than traditional ones that extract learner learning style once using ILS questionnaire.

Currently, we are in the process to start an implementation of an on-line learning environment to test the effectiveness of our suggested approach on learners process and achievements. We will build the same learning environment for two groups; (i) first group will be asked to answer a VAK questionnaire first time they log-in and the material will be displayed based on the questionnaire learning style. (ii) Second group; will be allowed to use the environment without asking them to answer any questionnaire, the dynamic technique will be monitoring their behaviour to detect learning style and will present learning material as per current detecting learning style.

\section{References}

[1] M. A. Abdullah, "Learning Style Classification Based on Student's Behavior in Moodle Learning Management System", Transactions on Machine Learning and Artificial Intelligence., vol.3, no. 1,(2015), pp. 28.

[2] N. Ahmad, Z. Tasir, J. Kasim and H. Sahat, "Automatic detection of learning styles in learning management systems by using literature-based method", Procedia-Social and Behavioral Sciences., vol. 103, (2013), pp. 181-189.

[3] V. Chang, "Review and discussion: e-learning for academia and industry", International Journal of Information Management., (2016).

[4] S. Cassidy*, "Learning styles: An overview of theories, models, and measures", Educational Psychology., vol. 24, no. 4,(2004), pp. 419-444.

[5] M. M. El-Bishouty, K. Saito, T. Chang and S. Graf, "Teaching Improvement Technologies for Adaptive and Personalized Learning Environments", Edited Kinshuk and R. Huang, Ubiquitous Learning Environments and Technologies, Springer Berlin Heidelberg. (2015), pp. 225-242.

[6] H. Fasihuddin, G. Skinner and R. Athauda, "Towards an adaptive model to personalize open learning environments using learning styles", 2014 International Conference on Information, Communication Technology and System (ICTS), Surabaya, Indonesia, (2014) September 24-24.

[7] J. Feldman, A. Monteserin and A. Amandi, "Automatic detection of learning styles: state of the art", Artificial Intelligence Review., vol. 44, no. 2, (2015), pp.157-186.

[8] S. Graf, "Adaptivity in learning management systems focussing on learning styles (Doctoral dissertation, Vienna University of Technology)", (2007).

[9] S. Graf, T. C. Liu, N. S. Chen and S. J. Yang, "Learning styles and cognitive traits-Their relationship and its benefits in web-based educational systems". Computers in Human Behavior., vol. 25, no. 6, (2009), pp.1280-1289.

[10] S. Graf and T. C. Liu, "Analysis of learners' navigational behaviour and their learning styles in an online course", Journal of Computer Assisted Learning., vol. 26, no. 2, (2010), pp. 116-131.

[11] S. Graf, K. B. Kinshuk, F. A. Khan, P. Maguire, A. Mahmoud, T. Rambharose and Q. Zhang, "Adaptivity and Personalization in Learning Systems based on Students' Characteristics and Context ", Proceedings of the 1st International Symposium on Smart Learning Environments (SLE), Edmonton, Canada, (2012) February 2-7.

[12] S. Gholami and M. S. Bagheri, "Relationship between VAK Learning Styles and Problem Solving Styles regarding Gender and Students' Fields of Study", Journal of Language Teaching and Research., vol. 4, no. 4,(2013), pp. 700-706.

[13] A. K. Hamada, M. Z. Rashad and M. G. Darwesh, "Behavior analysis in a learning environment to identify the suitable learning style", International Journal of Computer Science \& Information Technology (IJCSIT)., vol. 3, no. 2, (2013), pp. 48-59.

[14] T. Hamtini and H. Ateia, "A proposed dynamic technique for detecting learning style using literature based approach", 2015 IEEE Jordan Conference on Applied Electrical Engineering and Computing Technologies (AEECT), Amman, Jordan, (2015) November 3-5. 
[15] M. P. Hamzah, F. Yahya, W. Fatin, M. Noor, N. Maizura, M. N. Hassan and M. A. Shamsil, "Learning Style Detection by Using Literature-Based Approach: a Conceptual Design", Science International., vol. 26, no. 4, (2014), pp. 1493-1497.

[16] A. Latham, K. Crockett, and D. McLean, "An adaptation algorithm for an intelligent natural language tutoring system”. Computers \& Education, vol. 71, (2014), pp. 97-110.

[17] F. Mampadi, S. Y. Chen, G. Ghinea and M. P. Chen, "Design of adaptive hypermedia learning systems: A cognitive style approach", Computers \& Education., vol. 56, no. 4, (2011), pp. 1003-1011.

[18] H. Moayyeri, "The Impact of Undergraduate Students' Learning Preferences (VARK Model) on Their Language Achievement”, Journal of Language Teaching and Research., vol. 6, no. 1,(2015), pp.132-139.

[19] J. L. Moore, C. Dickson-Deane and K. Galyen, "E-Learning, on-line learning, and distance learning environments: Are they the same", The Internet and Higher Education., (2011), vol. 14, no. 2, pp. 129135.

[20] Ö. Özyurt and H. Özyurt, "Learning style based individualized adaptive e-learning environments: Content analysis of the articles published from 2005 to 2014", Computers in Human Behavior., vol. 52, (2015), pp.349-358.

[21] Z. A. H. Sfenrianto and H. Suhartanto, "An Automatic Approach for Identifying Triple-Factor in eLearning Process", International Journal of Computer Theory \& Engineering., vol. 5, no. 2, (2013), pp. 371-376.

[22] H. D. Surjono, "The design of adaptive e-Learning system based on student's learning styles", International Journal of Computer Science and Information Technology (IJCSIT)., (2011), vol. 2, no. 5,pp. 2350-2353.

[23] O. Tayo and O. Oluwakemi, "Educational Multimedia And Learning Style Preferences", British Journal of Education, (2015), vol. 3, no. 12, pp. 29-42.

[24] W. Yahya and N. Noor, "Decision Support System for Learning Disabilities Children in Detecting Visual-Auditory-Kinesthetic Learning Style", The 7th International Conference on Information Technology (ICIT), Jordan, (2015) May 12-15.

[25] M. Zajac, "Using learning styles to personalize on-line learning", Campus-wide information systems, (2009), vol. 26, no. 3, pp. 256-26.

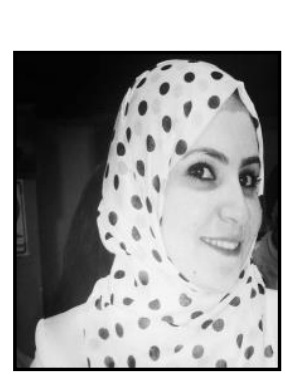

\section{Authors}

Hadeel Ateia, currently studying to achieve her Master degree in Information Systems at the King Abdullah II School for Information Technology, Department of Computer Information Systems, the University of Jordan, Amman, 11942, Jordan. E-mail: hadeel.ateia.ab@gmail.com

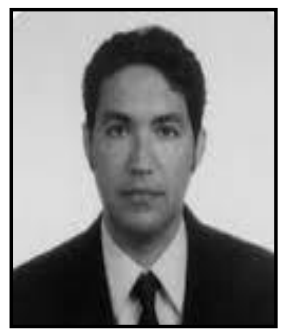

Thair Hamtini, is an associate professor with the King Abdullah II School for Information Technology, Department of Computer Information Systems, the University of Jordan, Amman, 11942, Jordan. E-mail: thamtini@ju.edu.jo 